\title{
Long-Term Variation of Global GEOV2 and MODIS Leaf Area Index (LAI) and Their Uncertainties: An Insight into the Product Stabilities
}

\author{
Hongliang Fang $\mathbb{D}$, ${ }^{1,2}$ Yao Wang $\mathbb{D}^{1,2}$ Yinghui Zhang $\mathbb{D}^{1,2}$ and Sijia Li $\mathbb{D}^{1,2}$ \\ ${ }^{1}$ LREIS, Institute of Geographic Sciences and Natural Resources Research, Chinese Academy of Sciences, Beijing 100101, China \\ ${ }^{2}$ College of Resources and Environment, University of Chinese Academy of Sciences, Beijing 100049, China \\ Correspondence should be addressed to Hongliang Fang; fanghl@lreis.ac.cn
}

Received 24 March 2021; Accepted 12 October 2021; Published 9 November 2021 Copyright (c) 2021 Hongliang Fang et al. Exclusive Licensee Aerospace Information Research Institute, Chinese Academy of
Sciences. Distributed under a Creative Commons Attribution License (CC BY 4.0).

\begin{abstract}
Leaf area index (LAI) is an essential climate variable that is crucial to understand the global vegetation change. Long-term satellite LAI products have been applied in many global vegetation change studies. However, these LAI products contain various uncertainties that are not been fully considered in current studies. The objective of this study is to explore the uncertainties in the global LAI products and the uncertainty variations. Two global LAI datasets-the European Geoland2 Version 2 (GEOV2) and Moderate Resolution Imaging Spectroradiometer (MODIS) (2003-2019)-were investigated. The qualitative quality flags (QQFs) and quantitative quality indicators (QQIs) embedded in the product quality layers were analyzed to identify the temporal anomalies in the quality profile. The results show that the global GEOV2 (0.042/10a) and MODIS (0.034/10a) LAI values have steadly increased from 2003 to 2019 . The global LAI uncertainty $(0.016 / 10 \mathrm{a})$ and relative uncertainty $(0.3 \% / 10 \mathrm{a})$ from GEOV2 have also increased gradually, especially during the growing season from April to October. The uncertainty increase is larger for woody biomes than for herbaceous types. Contrastingly, the MODIS LAI product uncertainty remained stable over the study period. The uncertainty increase indicated by GEOV2 is partly attributed to the sensor shift in the product series. Further algorithm enhancement is necessary to improve the cross-sensor performance. This study highlights the importance of studying the LAI uncertainty and the uncertainty variation. Temporal variations in the LAI products and the product quality revealed herein have significant implications on global vegetation change studies.
\end{abstract}

\section{Introduction}

Leaf area index (LAI) is defined as one half of the total green leaf area per unit ground surface area [1]. LAI has been recognized as a critical parameter to understand the terrestrial energy, carbon, and water cycles [2-4]. The global LAI has gradually increased, consistent with the global temperature change, since the industrial period $[5,6]$. Global long-term LAI products derived from satellite data show that the increasing trend has accelerated since $1982[1,7,8]$. The global LAI is projected to further increase in the 21 st century under future climate change scenarios [9]. However, regional decline of LAI exists in Eurasia, North and South America, and Southeast Asia caused by land use and land cover change (e.g., due to deforestation) $[5,10]$.
Understanding the uncertainties associated with the LAI products is paramount to understanding the global longterm LAI change. To meet the requirements of global climate modeling studies, the Globe Climate Observing System (GCOS) has proposed a guideline that requires a maximum uncertainty of $15 \%$ for global LAI products [11]. In response to the GCOS requirement, the Committee on Earth Observation Satellites (CEOS) has formed a Land Product Validation (LPV) subgroup to coordinate global validation studies for LAI and other land surface products (http://lpvs.gsfc .nasa.gov/). Under this framework, a series of comprehensive LAI validation studies have been conducted for a variety of land cover types at regional [12-15] and global scales [16-18]. Fang et al. [1] made a synthesis of current validation studies for the global moderate resolution LAI products 
and found that the median correlation coefficient $\left(R^{2}\right)$ between LAI products and reference data is around 0.62 and the root mean square error (RMSE) about 0.88 .

With the growing temporal coverage of product uncertainties, evaluating the product quality from a long-term perspective has become critical to ensure the product's correct application in global change studies. A change in data quality would imply that the temporal trend observed in the data is ambiguous [19].

The product quality stability is defined by GCOS as the maximum acceptable change in systematic error measured in decadal time scales [11]. In response to the increasing interest in the long-term variation of the LAI product uncertainty, GCOS proposed a stability requirement at the maximum of $10 \%$ or 0.25 per decade, in relative and absolute terms, respectively, for the LAI product [11]. Clearly, the product quality stability defined by GCOS [11] is different from the product stability explored in some existing studies [7, 12, 20, 21].

Nevertheless, because of the lack of long-term reference data, almost all current validation studies have focused on estimating the product uncertainties rather than on product quality stability [1]. Padilla et al. [22] evaluated the temporal stability of three global burned area products over seven sites and found a monotonic trend in accuracy over time. Their study represents one of the few attempts to quantify the temporal stability of satellite products following the GCOS definition. However, due to the limited number of sampling sites, it is difficult to claim that the burned area products had shown temporal instability [22]. The situation is similar for the global LAI products. Due to the lack of reference data, only a few studies have explored the long-term variation of the LAI product theoretical quality $[7,21,23]$.

In distributing the LAI values, many LAI products also provide the quality assessment (QA) information that includes the qualitative quality flags (QQFs) and quantitative quality indicators (QQIs). The QQFs are related to the product processing status and have been frequently referred to as a guideline in many applications. The QQIs, on the other hand, provide the theoretical uncertainty information but have been less explored. Fang et al. [24] made a first attempt to intercompare the global LAI products and their theoretical uncertainties obtained from the product QQIs. However, the study should be improved with the availability of new LAI products. More importantly, the temporal variation of the QQI information was not explored in the earlier study [24]. In a following study, Jiang et al. [7] analyzed the long-term variation of global LAI and their uncertainties. In the study, product theoretical uncertainties were derived using a collocation error model and the temporal variation of the uncertainties was calculated as twice the standard deviation of the time series [7]. In a more recent study, Yan et al. [21] made a temporal analysis of the MODIS LAI and QQI. The LAI product explored in the study was generated from the MODIS sensor onboard Terra [21].

As a preliminary study, Fang et al. [23] proposed to investigate the long-term variation of global GEOV2 and MODIS LAI products and their theoretical uncertainties.
However, in that study, the spatial and temporal analysis was limited. All available GEOV2 pixels were analyzed without proper consideration of the product QQIs, and the LAI was underestimated [23]. An in-depth assessment of the quantitative indicators is thus critical in order to properly investigate the global LAI and their uncertainties.

The present study is aimed at investigating the long-term variation of the GEOV2 and MODIS LAI products and their uncertainties through a comprehensive analysis of the product QQF and QQI information. This study has significantly enhanced over existing studies. Compared to Fang et al. [23], the present study fully analyzed the product QQI and utilized only the best retrievals in the analysis. The longterm product quality variation was calculated as the rate of change of the product uncertainty per decade. Both spatial and temporal analyses were also significantly expanded. Different from Yan et al. [21], the present study is aimed at examining the LAI product generated by MODIS onboard both Terra and Aqua (MCD15A2). Some validation studies have reported that the combined product shows better agreement with field measurements [14, 16, 25]. In particular, this study intends to investigate the temporal variability of the product relative uncertainty, which has not been explored in other studies.

\section{Data and Method}

2.1. GEOV2 LAI. The GEOV2 (V2.0) LAI (Table 1) is derived from the European Geoland2/BioPar project from the SPOT/VEGETATION (SPOT/VGT) and the PROBA$\mathrm{V}(\mathrm{GEOV} 2 / \mathrm{PV})$ observations at $1 / 112^{\circ}$ and a 10 -day time step (http://land.copernicus.eu/global/products/lai). When the SPOT/VGT mission concluded in May 2014, the GEOV2/VGT algorithm was adapted and applied to the PROBA-V data (GEOV2/PV). The MODIS (C5) and CYCLOPES (V3.1) products are first combined to generate an improved LAI estimate [26].

$$
\mathrm{LAI}_{\text {fused }}=w \cdot \mathrm{LAI}_{\mathrm{MOD}}+(1-w) \cdot \mathrm{LAI}_{\mathrm{CYC}}, \quad \text { with } w=\min \left(1, \frac{1}{4} \mathrm{LAI}_{\mathrm{CYC}}\right) \text {, }
$$

where "LAI $\mathrm{L}_{\text {fused }}$ " "LAI $\mathrm{LOD}_{\mathrm{MOD}}$ " and "LAI $\mathrm{CYC}$ " correspond to the fused, MODIS, and CYCLOPES products, respectively. The weight, $w$, is driven by $\mathrm{LAI}_{\mathrm{CYC}}$ since it appears to be more stable at low LAI values than that of MODIS. The threshold value $\left(\mathrm{LAI}_{\mathrm{CYC}}=4\right)$ corresponds to the value when $\mathrm{LAI}_{\mathrm{CYC}}$ begins to saturate. A neural network training process is performed between the fused LAI and the SPOT/VEGETATION and PROBA-V daily reflectance data over the global BELMANIP sites [27]. The landscape level clumping is accounted for in CYCLOPES through the separation of pure vegetation and bare soil in the pixels [28]. A multistep filtering approach is applied to eliminate noisy data mainly affected by atmospheric effects and snow cover [29]. The approach is based on an iterative upper envelope process and prior knowledge on the expected seasonality. The retrieval methods are categorized based on the product quality layer (QFLAG): (1) direct retrieval for clear land 
TABLE 1: Characterization of the moderate resolution LAI products investigated in the study. LUT, NIR, NN, and SWIR stand for look-up table, near-infrared, neural network method, and shortwave infrared, respectively.

\begin{tabular}{|c|c|c|c|c|c|c|c|}
\hline Product* & Sensor & $\begin{array}{c}\text { Spatial } \\
\text { resolution }\end{array}$ & $\begin{array}{l}\text { Temporal } \\
\text { resolution }\end{array}$ & Algorithm & Period & $\begin{array}{l}\text { Uncertainty } \\
\text { provided }\end{array}$ & Reference \\
\hline $\begin{array}{l}\text { GEOV2 } \\
(\mathrm{V} 2.0)\end{array}$ & $\begin{array}{c}\text { VEGETATION/SPOT } \\
(1999.1-2013.12) \\
\text { PROBA-V }(2014.1+)\end{array}$ & $1 / 112^{\circ}$ & 10-day & $\begin{array}{l}\text { NN (red, NIR, SWIR, } \\
\text { observation geometry) }\end{array}$ & $\begin{array}{l}1999.1- \\
2020.6\end{array}$ & Yes & $\begin{array}{l}\text { Verger } \\
\text { et al. [35] }\end{array}$ \\
\hline $\begin{array}{l}\text { MODIS } \\
\text { (C6) }\end{array}$ & MODIS/Terra+Aqua & $500 \mathrm{~m}$ & 8-day & LUT (red, NIR) & $2002.7+$ & Yes & $\begin{array}{c}\text { Yan et al. } \\
{[30,31]}\end{array}$ \\
\hline
\end{tabular}

*GEOV2 (http://land.copernicus.eu/global/products/lai), MODIS (https://earthdata.nasa.gov/).

TABLE 2: Quality control measures used in the LAI products. QQFs: qualitative quality flags; QQIs: quantitative quality indicators.

\begin{tabular}{lccccc}
\hline Product & Data format & QQFs & QQIs & Quality control* & Usage in the study \\
\hline GEOV2 & NetCDF & LAI-QFLAG & RMSE & QQF $=(000,010)$ & Direct retrievals \\
MODIS & HDF & FparLAI_QC & LaiStdDev & QQF $=(000,001)$ & Main retrievals \\
\hline
\end{tabular}

${ }^{*}$ Numbers in the brackets indicate the bit combinations of QQF.

observations, clear high latitude observations for latitude and sensor zenith angle greater than $55^{\circ}$ and $70^{\circ}$, respectively, evergreen broadleaf forest observations with enough observations, pixels identified as bare soil with enough observations, and observations corrected at high latitude effects, (2) climatological retrieval for pixels filled with climatology, and (3) interpolated retrieval for pixels filled by interpolation. The quantitative uncertainties are computed as the RMSE between the final 10-day value and the daily estimates in the compositing period (Table 2).

2.2. MODIS LAI. The MODIS collection 6 (C6) product, acquired from the combined Terra and Aqua platform (MCD15A2H, Table 1), is generated every 8 days with a $500 \mathrm{~m}$ spatial resolution (https://earthdata.nasa.gov/). The main algorithm employs a look-up table (LUT) method simulated from a three-dimensional (3D) radiative transfer model to derive LAI from the daily red and near-infrared (NIR) reflectance data (MOD09GA, $500 \mathrm{~m}, \mathrm{C6}$ ) and the multiyear land cover product (MCD12Q1, 500 m) [30, 31]. The LUT method searches for all probable estimates from the observed directional reflectance for a specific biome type. The mean LAI value averaged over all acceptable estimates is taken as the solution, and the standard deviation (LaiStdDev) of the candidate LAI values serves as a measure of precision. In addition to the main algorithm, a backup algorithm is constructed based on the empirical relationship between LAI and the normalized difference vegetation index (NDVI) for different biome types [32]. The eight biome types used to constrain the vegetation optical and structural parameter spaces are (1) grasses/cereal crops, (2) shrubs, (3) broadleaf crops, (4) savanna, (5) evergreen broadleaf forest (EBF), (6) deciduous broadleaf forest (DBF), (7) evergreen needleleaf forest (ENF), and (8) deciduous needleleaf forest (DNF) [33]. A priori leaf clumping information was assigned for different biome types during the modeling and retrieval processes [34]. A quality control mask indicates whether the LAI value is derived from the main algorithm or from the empirical backup algorithm (Table 2).

2.3. Data Analysis. The product quality control information was first analyzed. Cloudy pixels were first masked out, and only good retrievals were used in the following analysis. All valid GEOV2 pixels from the direct retrieval methods, i.e., not gap-filled or interpolated, and all MODIS data from the main retrieval algorithm were extracted and processed. All global tiles from 2003 to 2019 were mosaicked and resampled to a $0.05^{\circ}(\sim 5.6 \mathrm{~km}$ at the Equator) spatial resolution using the nearest neighbor resampling method in the Plate Carée projection. The product QQI was analyzed to calculate the long-term quality variability. As noted, the GEOV2 QQI represents the product variability within the compositing period, while the MODIS QQI quantifies the product theoretical uncertainty. The datasets and their QQIs were averaged to a monthly time step that enabled direct comparison of the products. The corrupted data and filled values were not included in the aggregation. The correlation between QQI and LAI was calculated to analyze the association between them. The relative QQI was simply calculated as the ratio of QQI to LAI.

For consistency, the 2003 MODIS biome type map provided in the $0.05^{\circ} \mathrm{MODIS} /$ Terra+Aqua collection 5 land cover type product (MCD12C1) was used as a base map for LAI product analysis [36]. For computation efficiency and compatibility with the biome map, all datasets were analyzed globally at $0.05^{\circ}$ grid cells.

To reveal the altitudinal trend of LAI quality, the $90 \mathrm{~m}$ Shuttle Radar Topography Mission (SRTM) V4 altitude data were obtained from the CGIAR-CSI site (http://srtm.csi .cgiar.org/index.asp). The LAI, uncertainty, and relative uncertainty patterns were examined along the latitude and altitude ranges. The long-term trends were retrieved by linear regressions, and the significance of the trend was estimated using the Mann-Kendall trend test [22]. The two 


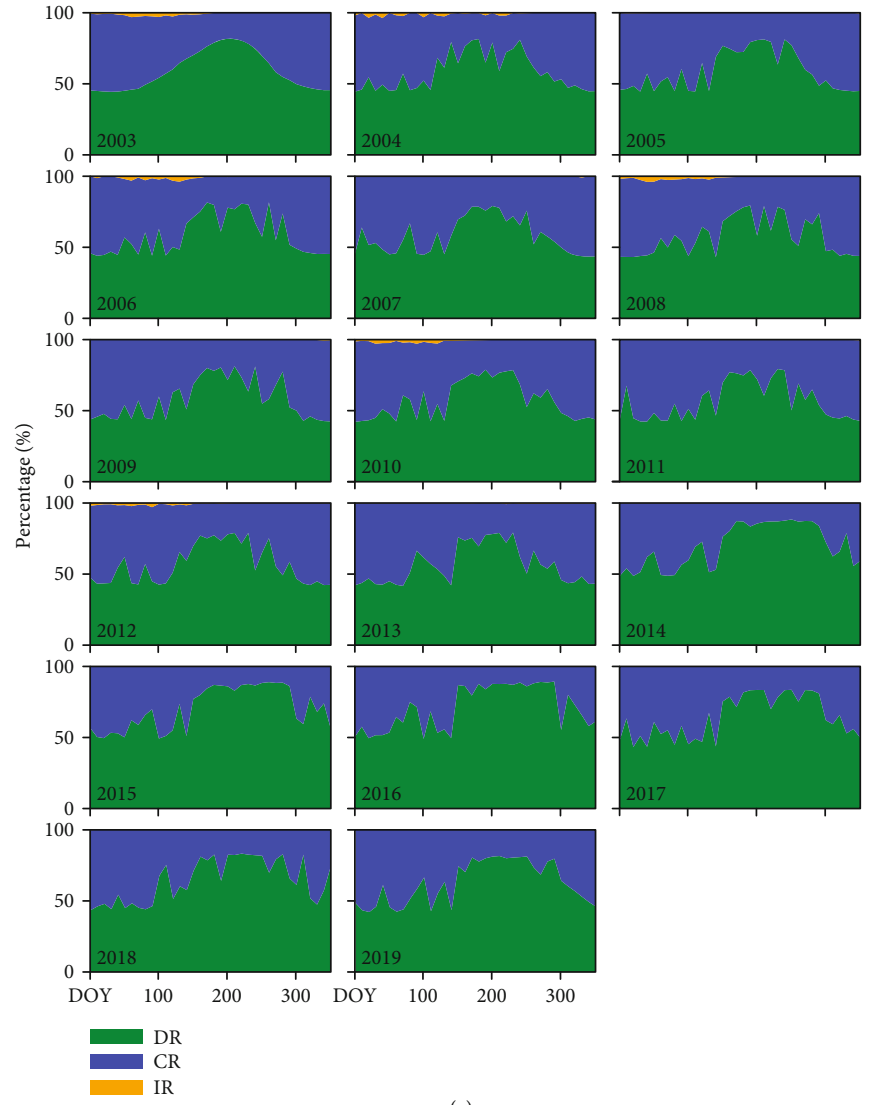

(a)

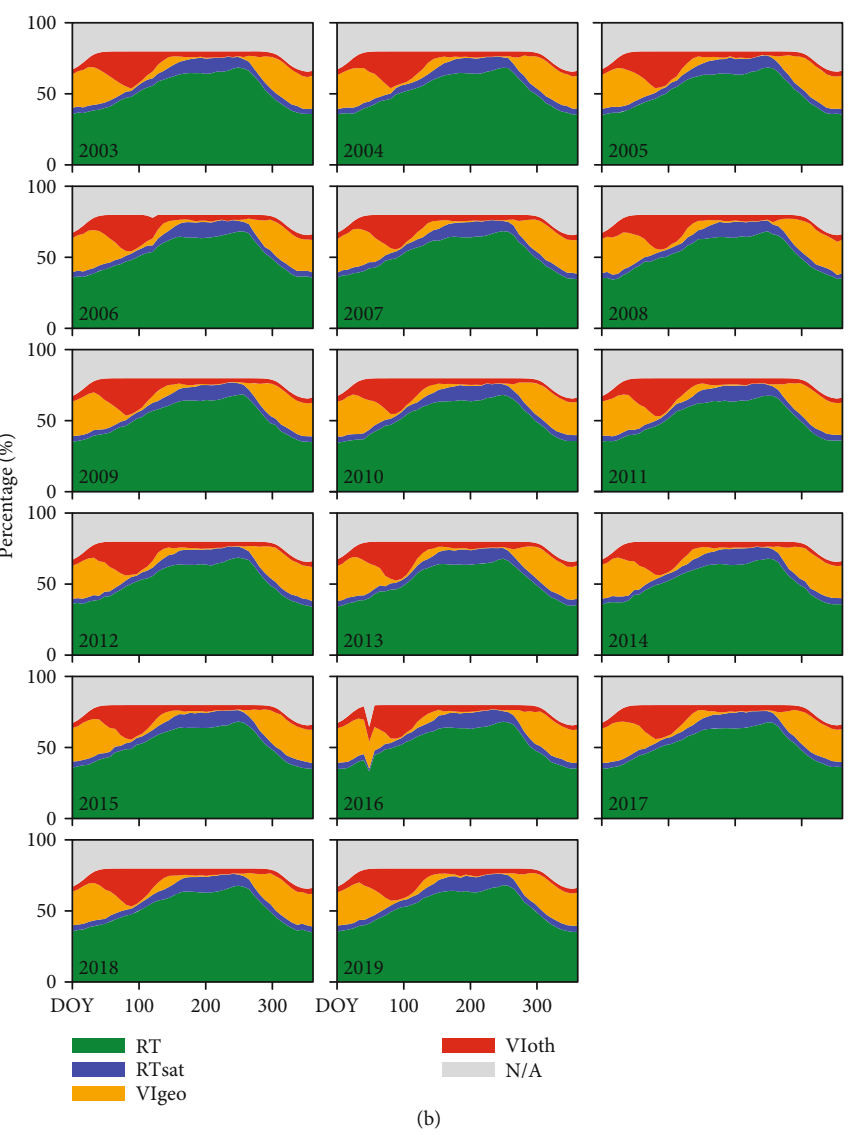

(b)

FIgure 1: Temporal variation of LAI qualitative quality flags (QQFs) for different years (2003-2019): (a) GEOV2 and (b) MODIS. DOY: day-of-year; DR: direct retrieval; CR: climatological retrieval; IR: interpolated retrieval; RT and RTsat: main radiative transfer (RT) method used with the best result and with saturation, respectively; VIgeo and VIoth: empirical vegetation index (VI) algorithm used due to bad geometry and other problems, respectively; N/A: no valid retrieval.

hemispheres were not separated in our calculation as our primary objective was to obtain an intercomparison of the different products.

\section{Results}

3.1. Spatial Pattern. Figure 1 shows that $50-80 \%$ of the GEOV2 pixels are from the direct retrieval method, 20$40 \%$ from the climatological retrieval method, and only $1 \%$ from the interpolated retrieval method. The MODIS LAI is mainly retrieved with the main radiative transfer algorithm. The average percentage of the main retrieval pixels reaches $62.8 \%$ from 150 to 300 day-of-year (DOY). A large number of MODIS pixels are still retrieved with the empirical backup algorithm, especially during the winter season.

GEOV2 and MODIS display similar spatial and temporal pattern for LAI values, uncertainties, and relative uncertainties (Figure 2). Generally, high LAI values are distributed in the tropical and boreal regions and very low values in the arid and semiarid regions. The overall GEOV2 LAI (1.16) is slightly lower than the MODIS LAI (1.28) (Table 3(a)). However, the GEOV2 LAI is slightly higher in the boreal and Amazon regions in July (Figures 2(a)-2(d)).
The spatial distribution of the uncertainty maps are correlated with the LAI distribution (Figures 2(e)-2(h)). Higher uncertainties are generally distributed in the tropical and boreal regions. The spatial patterns of the GEOV2 and MODIS uncertainties are also similar, although GEOV2 exhibits a slightly higher uncertainty. The spatial distribution of relative uncertainties demonstrates a distinct pattern; the higher values are located in the tree-grass transition regions such as in western Asia and Australia (Figures 2(i)-2(l)). Globally, the GEOV2 uncertainty (0.22) is about $10 \%$ higher than that of the MODIS $(0.20$, Table 3(a)). The overall relative uncertainties are similar for both products $(\sim 16.6 \%)$, but the values are highly variable for forest types while the lowest relative uncertainties are found for EBF (Table 3(a)).

Figure 3 shows that the LAI product uncertainties are moderately correlated with the LAI values, especially for LAI $<5.0$. On average, the GEOV2 and MODIS uncertainties are about $11-12 \%$ of the LAI values, but showing substantial variabilities. The strongest uncertainty variation is observed for LAI > 2.0. A large portion of the GEOV2 uncertainty is $>1.5$, whereas the MODIS uncertainties are mostly $<1.5$. Both products display a cluster of pixels at LAI $>5.0$, although with small uncertainties $(<0.5)$. This higher LAI cluster is a typical characteristic of the EBF biome type (Figure S1). 

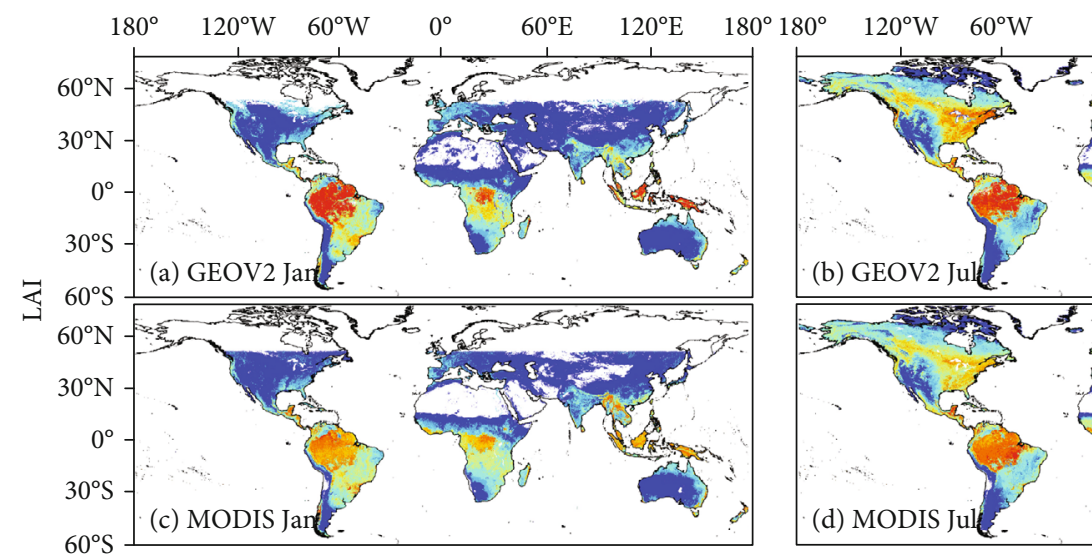

$0^{\circ} \quad 60^{\circ} \mathrm{E} \quad 120^{\circ} \mathrm{E} \quad 180^{\circ}$
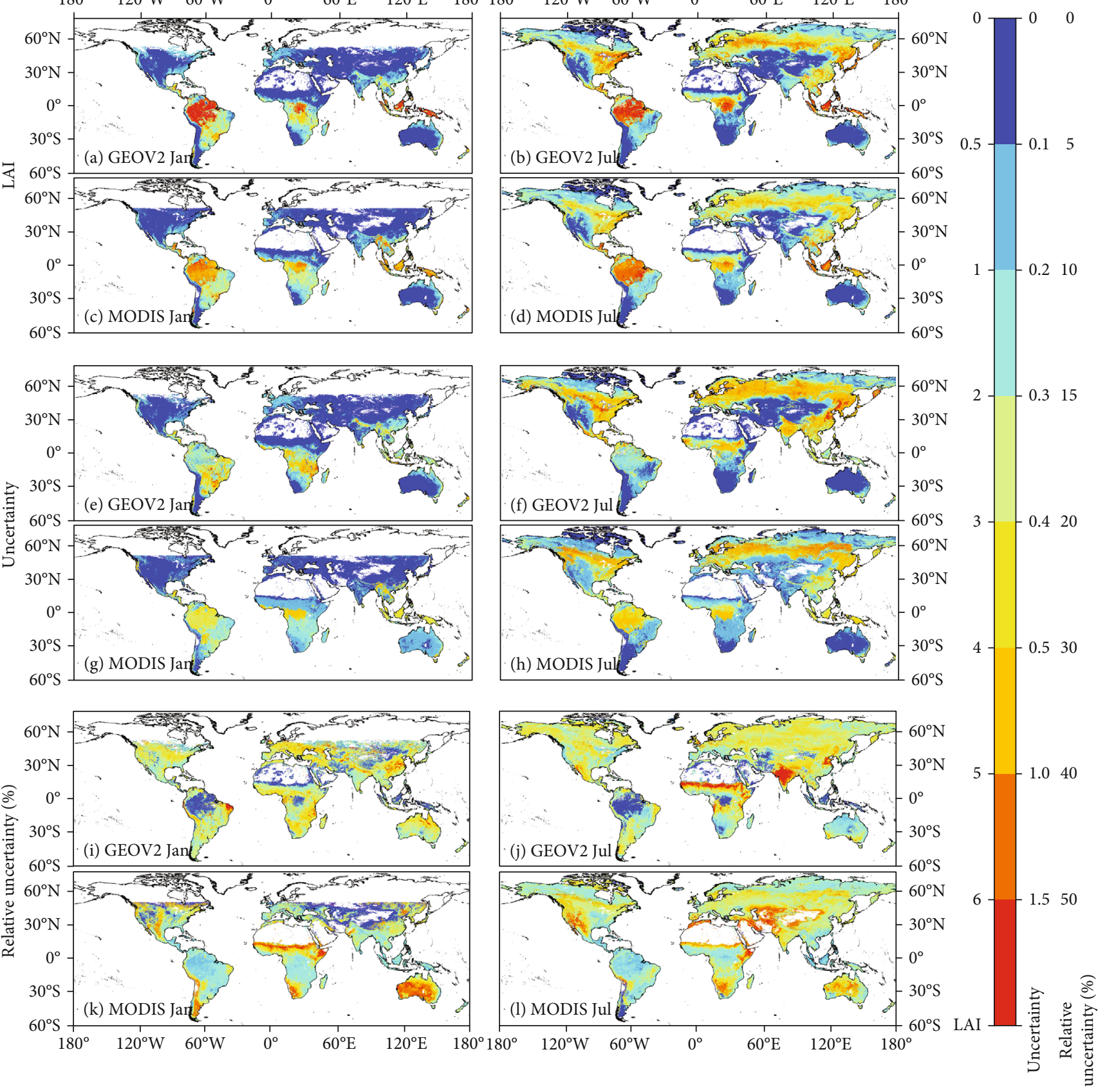

Figure 2: Global (a-d) mean LAI, (e-h) uncertainty, and (i-l) relative uncertainty maps derived from GEOV2 and MODIS $\left(0.05^{\circ}\right)$ in January (left panels) and July (right panels), respectively, 2003-2019.

\subsection{Temporal Variation}

3.2.1. Overall Variation Profile. Figure 4 shows the global variation of LAI, uncertainty, and relative uncertainty from 2003 to 2019. Both products show steady increases in LAI from 2003 to 2019 ( 0.03/10a); however, the increase in GEOV2 is not significant under the Mann-Kendall trend test $(p=0.09)$. The GEOV2 LAI uncertainty shows a small increase on a global trend of $0.012 / 10 \mathrm{a}$ since $2003(p<0.05$ ) . In contrast, the MODIS uncertainty $(\sim 0.20)$ remains stable over the same period (Figure 4(b)). For both products, the relative uncertainties remain stable over the study period
( 17\%). The Mann-Kendall statistical evaluation reveals negligible variation over the years for the MODIS uncertainty and relative uncertainty.

3.2.2. Variation Trend Map. Figure 5 shows the spatial pattern of the temporal variations in LAI, uncertainty, and relative uncertainty from 2003 to 2019. Differences exist among the LAI products while calculating the long-term trend in the boreal and tropical regions. For both products, positive LAI trends are observed in South America, Europe, China, and India. Negative trends are sparsely distributed in the 
TABLE 3: (a) Global mean LAI values, uncertainties, and relative uncertainties and (b) their long-term trend for different biome types (20032019). The last column is calculated from the global average of all vegetated pixels. Crop-C and Crop-B refer to the cereal crops and broadleaf crops, respectively. EBF, DBF, ENF, and DNF stand for the evergreen broadleaf forest, deciduous broadleaf forest, evergreen needleleaf forest, and deciduous needleleaf forest, respectively. Non- $\mathrm{V}$ indicates the nonvegetated type. In all statistics, positive ( $>0)$ values were considered for LAI and nonnegative $(\geq 0)$ values for uncertainty and relative uncertainty.

\begin{tabular}{|c|c|c|c|c|c|c|c|c|c|c|}
\hline & Biome types & Grass/Crop-C & Shrub & Crop-B & Savanna & $\mathrm{EBF}$ & $\mathrm{DBF}$ & ENF & DNF & Globe \\
\hline \multicolumn{11}{|l|}{ (a) Mean values } \\
\hline \multirow{2}{*}{ Mean LAI } & GEOV2 & 0.63 & 0.32 & 1.07 & 1.31 & 4.84 & 2.10 & 1.40 & 1.32 & 1.16 \\
\hline & MODIS & 0.64 & 0.35 & 0.98 & 1.41 & 4.79 & 2.05 & 1.45 & 1.38 & 1.28 \\
\hline \multirow{2}{*}{ Uncertainty } & GEOV2 & 0.16 & 0.07 & 0.29 & 0.29 & 0.37 & 0.51 & 0.34 & 0.39 & 0.22 \\
\hline & MODIS & 0.12 & 0.08 & 0.15 & 0.23 & 0.44 & 0.41 & 0.43 & 0.37 & 0.20 \\
\hline \multirow{2}{*}{ Relative uncertainty (\%) } & GEOV2 & 19.1 & 12.5 & 26.1 & 17.0 & 9.4 & 22.7 & 14.2 & 18.8 & 16.6 \\
\hline & MODIS & 18.7 & 18.8 & 17.9 & 13.6 & 10.6 & 18.2 & 22.6 & 20.3 & 16.7 \\
\hline \multicolumn{11}{|c|}{ (b) Long-term trend (per decade) } \\
\hline \multirow{2}{*}{ Mean LAI $\left(10^{-2}\right)$} & GEOV2 & 5.3 & 6.4 & 5.9 & 11.4 & -15.1 & 13.5 & 10.2 & 11.9 & 4.2 \\
\hline & MODIS & 3.5 & 1.8 & 7.2 & 5 & -0.5 & 4.8 & 3.7 & 3.2 & 3.4 \\
\hline \multirow{2}{*}{ Uncertainty $\left(10^{-2}\right)$} & GEOV2 & 1.2 & 1 & 2.8 & 4 & -4.1 & 5.3 & 5.2 & 5.7 & 1.6 \\
\hline & MODIS & 0.5 & 0.2 & 1.1 & 0.5 & -0.6 & 0.6 & 0.6 & 0.4 & 0.4 \\
\hline \multirow{2}{*}{ Relative uncertainty (\%) } & GEOV2 & -0.5 & 0.2 & -0.6 & 2.2 & -1.3 & 2.7 & 3.5 & 4.9 & 0.3 \\
\hline & MODIS & -0.1 & -0.2 & -0.4 & -0.1 & -0.1 & -0.1 & -0.1 & 0.1 & -0.1 \\
\hline
\end{tabular}
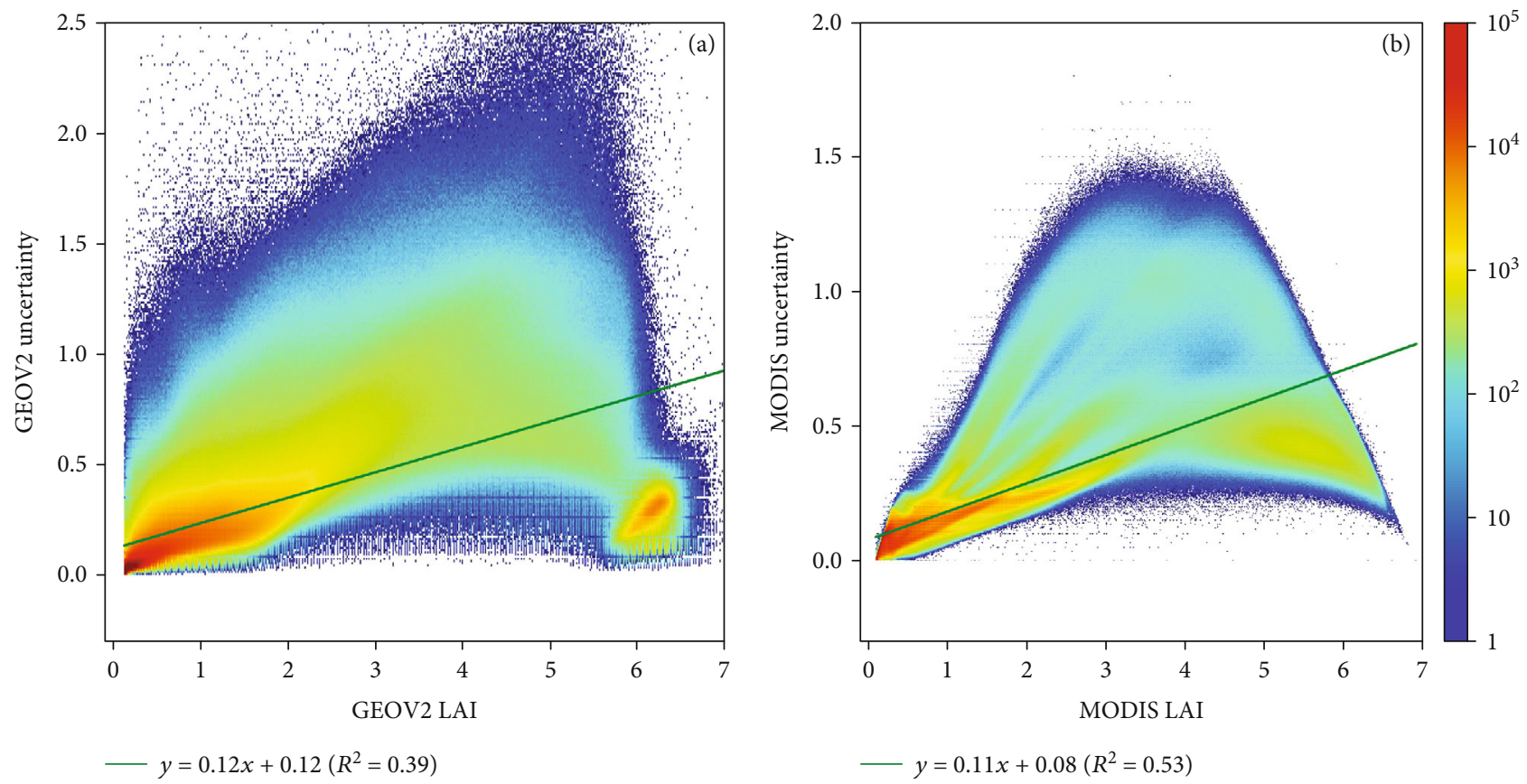

FIGURE 3: Density scatter plots between LAI and the associated uncertainties for (a) GEOV2 and (b) MODIS. Calculated from monthly averaged pixel data $\left(0.05^{\circ}\right)$.

tropical, boreal, and the eastern part of North and South American regions.

The increase of uncertainty for GEOV2 is primarily located in the boreal and tropical forest areas and, to a smaller extent, in China and the eastern part of the United States. For MODIS, the variation of uncertainty is nearly stable.
The relative uncertainties exhibit trends of $0.3 \%$ and $-0.1 \%$ per decade for GEOV2 and MODIS, respectively (Table 3(b)). With regard to GEOV2, the relative uncertainty increases in the boreal region, which coincides with the uncertainty change. The MODIS relative uncertainty displays a negligible decline in global vegetated areas (Figure 5). 

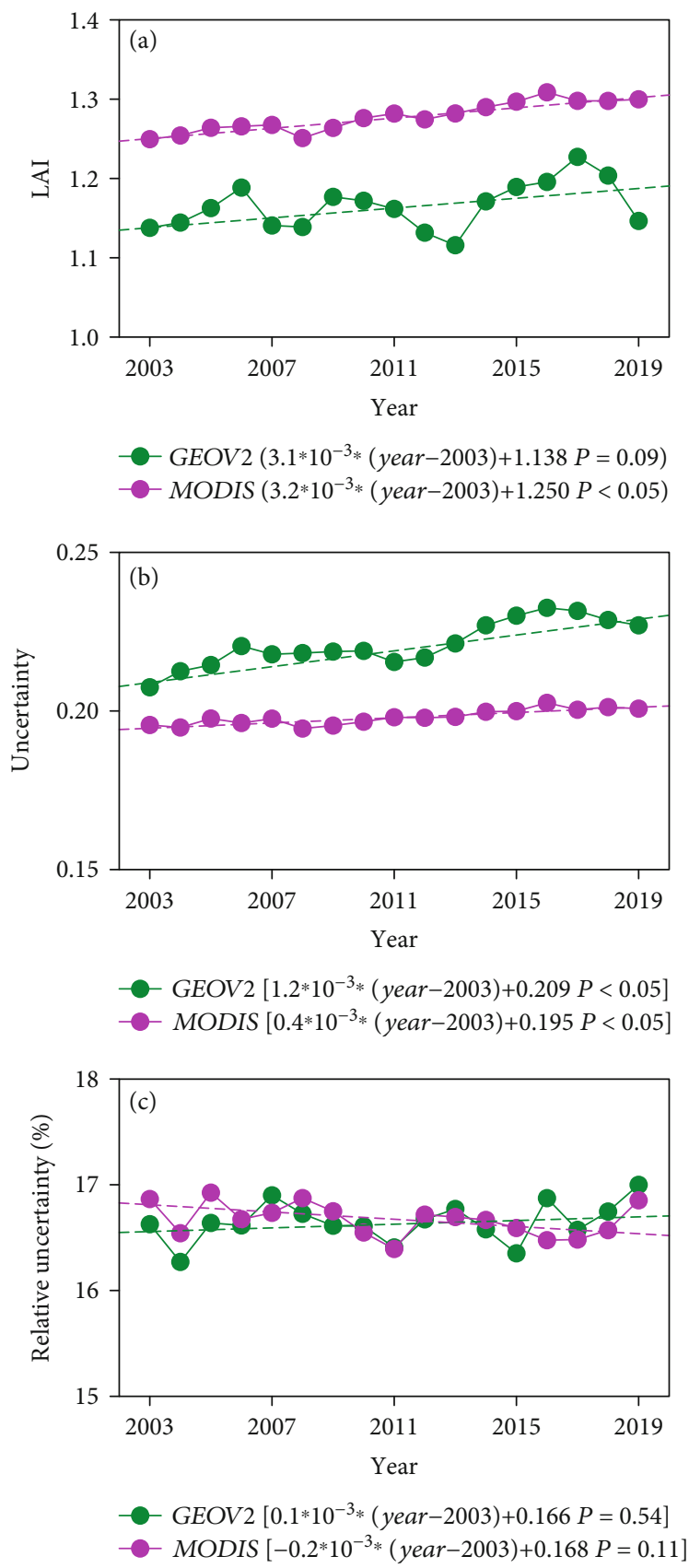

FIGURE 4: Temporal variation of global (a) mean LAI, (b) uncertainty, and (c) relative uncertainty derived from GEOV2 (green) and MODIS (purple) $\left(0.05^{\circ}\right)$. Trend lines are calculated from the global average values (dots).

3.2.3. Different Biome Types. Figure 6 shows the long-term variation of LAI, uncertainty, and relative uncertainty for different biome types. For GEOV2, the LAI and uncertainty values are nearly stable for grasses and crops from 2003 to 2019, but show a small increase for shrubs and savannas since 2014. In a similar way, DBF, ENF, and DNF show an increase in LAI and uncertainty since 2014, but EBF shows a strange decrease in 2014 and an increase in 2017. The calculated relative uncertainties for GEOV2 decrease for grasses, crops, and EBF after 2014, but increase for all other biome types since the year. The sharp variations in LAI, uncertainty, and relative uncertainty for GEOV2 in 2014 are attributed to the sensor shift in that year and the limitation of the algorithm to adapt to the new sensor. Among the nonforest types, savanna displays a clear increase in LAI $(0.114 / 10 \mathrm{a})$, uncertainty $(0.040 / 10 \mathrm{a})$, and relative uncertainty $(2.2 \% / 10 \mathrm{a})$ during the period (Table $3(\mathrm{~b})$ ).

3.2.4. Different Seasons. Figure 7 shows that the LAI increase is higher in March-April-May (MAM) and June-JulyAugust (JJA) than that in September-October-November (SON) and December-January-February (DJF). For GEOV2, the uncertainties are higher in summer (JJA) than those in other seasons, although the relative uncertainties are higher 


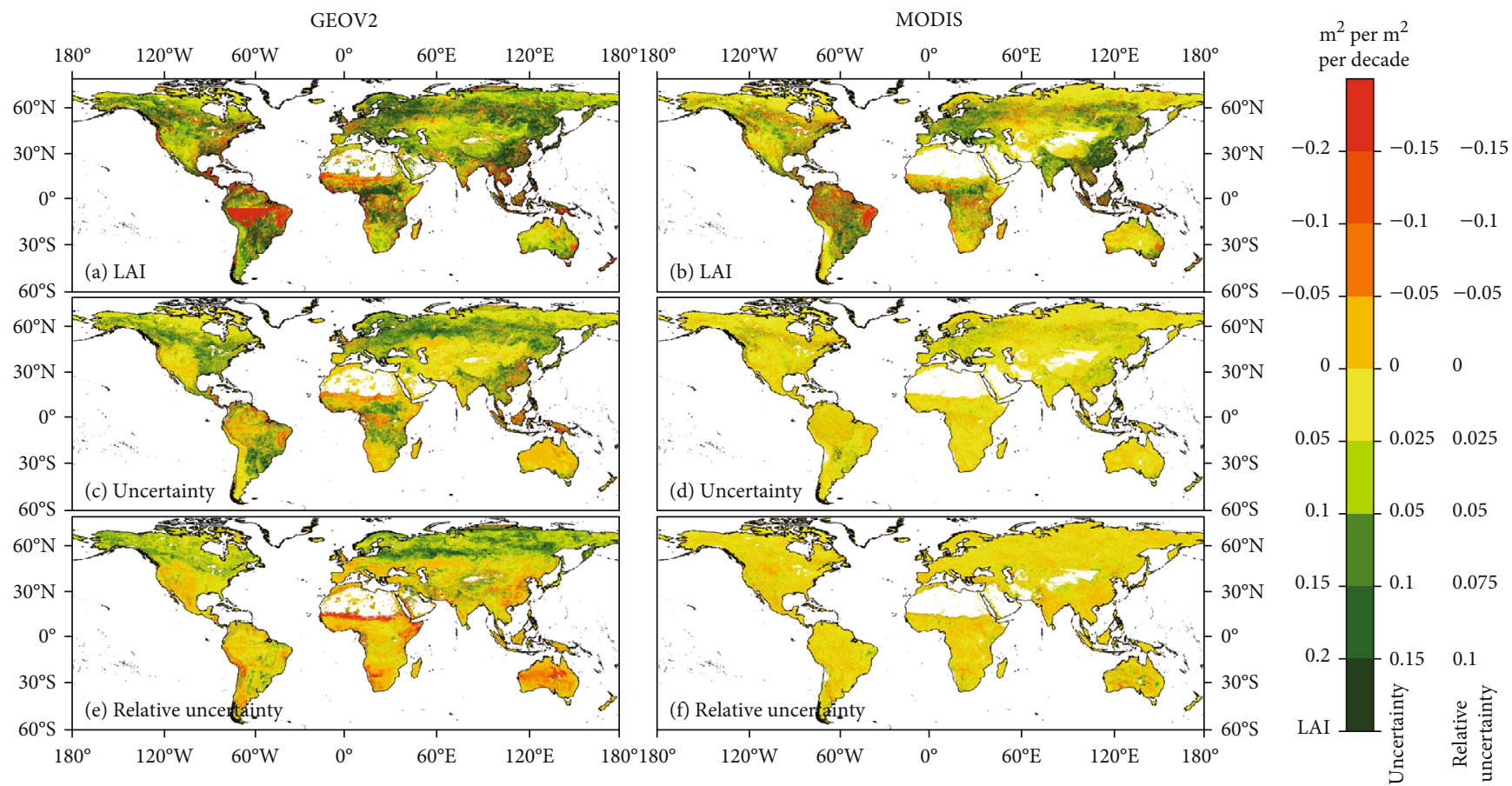

FIGURE 5: Long-term trend of the global GEOV2 and MODIS (a, b) LAI, (c, d) uncertainty, and (e, f) relative uncertainty from 2003 to 2019.
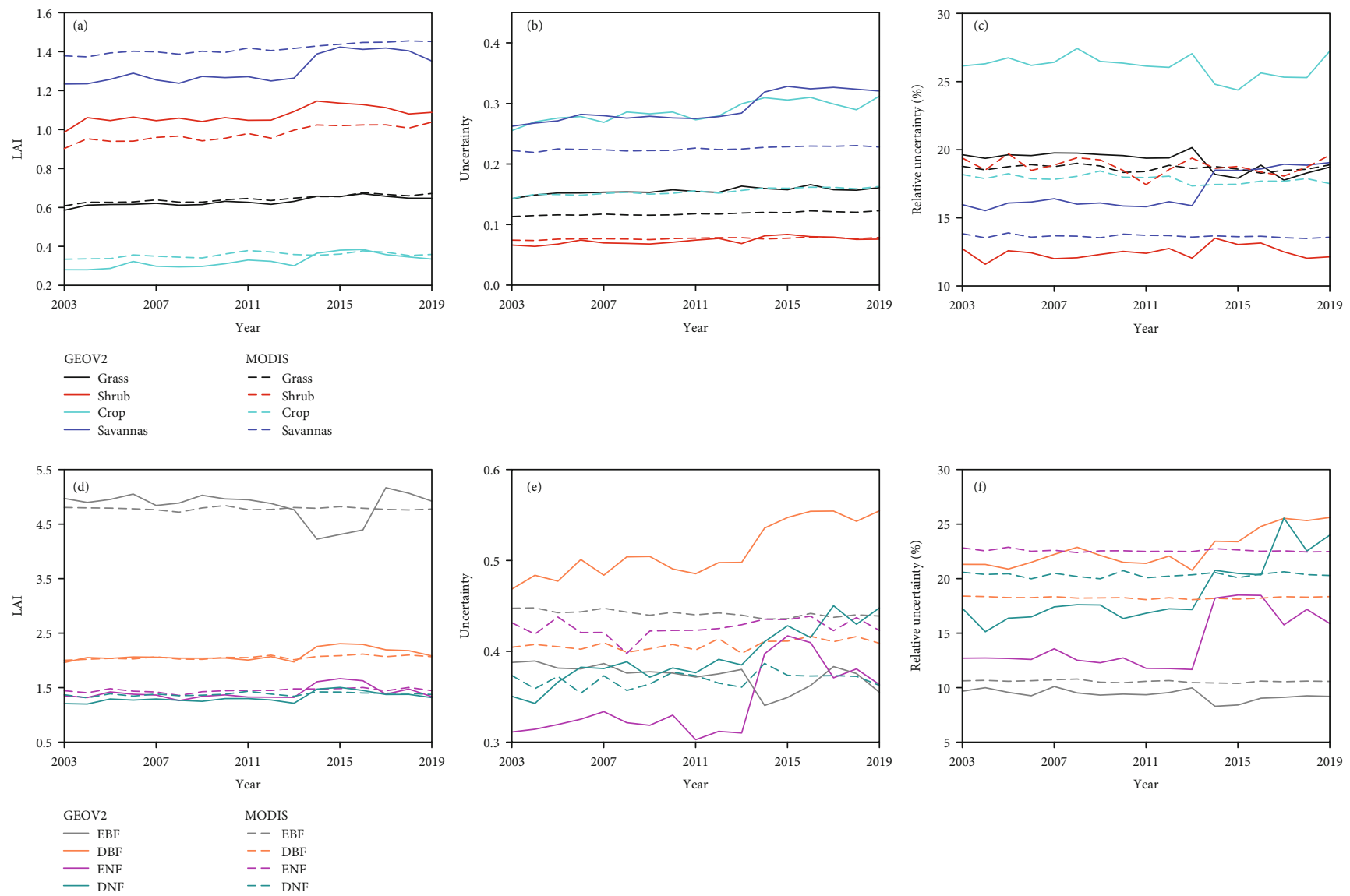

FIgURE 6: Temporal variation of $(a, d)$ LAI, $(b, e)$ uncertainty, and $(c, f)$ relative uncertainty for $(d-f)$ forest and (a-c) nonforest biome types. 

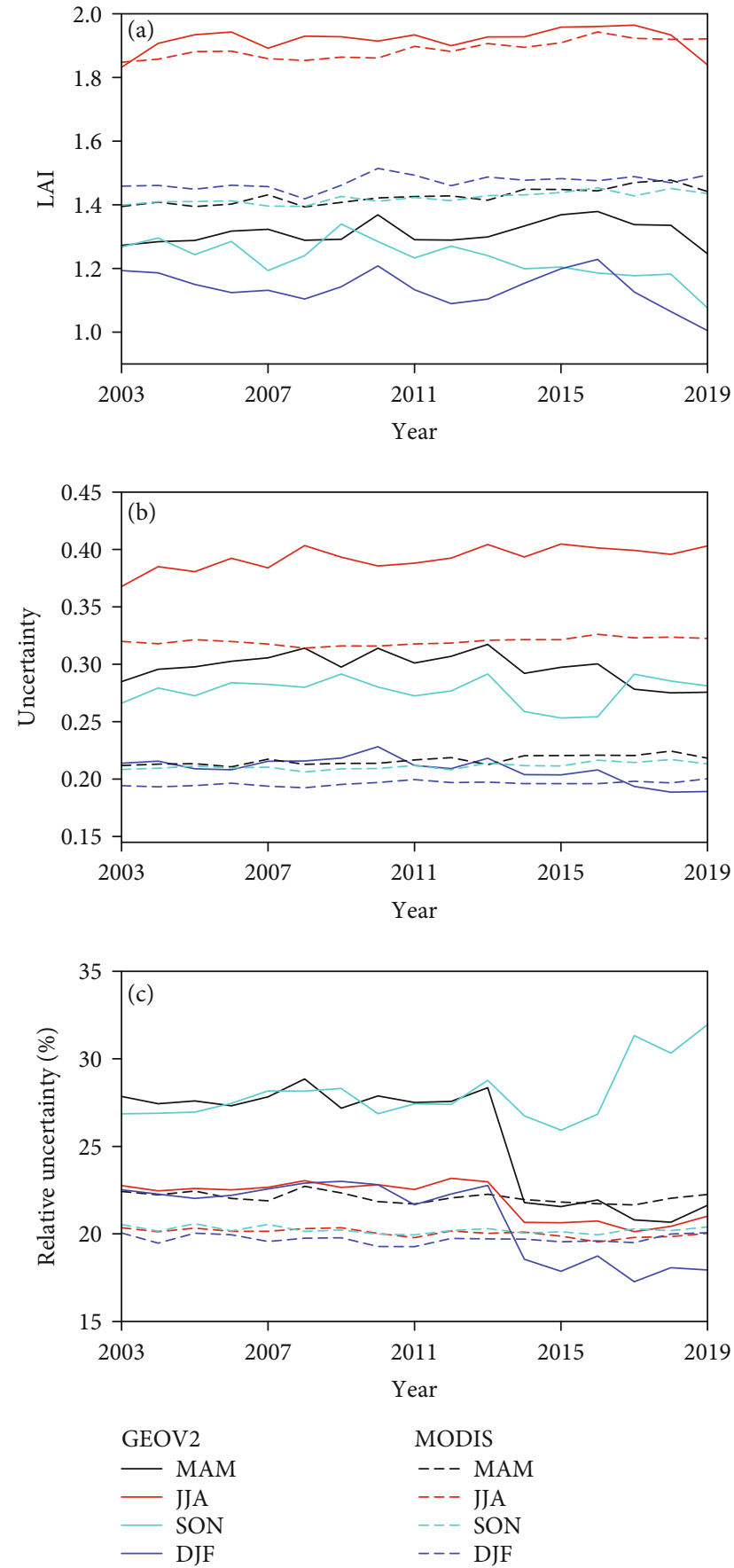

Figure 7: Variation of global (a) LAI, (b) uncertainty, and (c) relative uncertainty for different seasons. MAM: March-AprilMay; JJA: June-July-August; SON: September-October-November; DJF: December-January-February.

in MAM and SON than in JJA and DJF (Table 4). The GEOV2 uncertainties show a slight increase in JJA but a decrease in DJF. GEOV2 exhibits a sharp decreasing trend in relative uncertainties in MAM, JJA, and DJF, but an increasing trend in SON, especially after 2014. The MODIS LAI and uncertainty profiles show minor increases in all seasons, while the relative uncertainties decrease for all seasons.
TABLE 4: Global average LAI, uncertainty, and relative uncertainty (first row) and their long-term trend (per decade, italicized row) for different seasons (2003-2019). MAM: March-April-May; JJA: JuneJuly-August; SON: September-October-November; DJF: December-January-February.

\begin{tabular}{lcccccc}
\hline \multirow{2}{*}{ Seasons } & \multicolumn{2}{c}{ LAI } & \multicolumn{2}{c}{ Uncertainty } & \multicolumn{2}{c}{ Relative } \\
& GEOV2 & MODIS & GEOV2 & MODIS & GEOV2 & MODIS \\
\hline \multirow{2}{*}{ MAM } & 1.31 & 1.43 & 0.30 & 0.22 & 25.5 & 22.1 \\
& 0.031 & 0.044 & -0.006 & 0.007 & -4.3 & -0.3 \\
& 1.92 & 1.89 & 0.39 & 0.32 & 22.0 & 20.1 \\
JJA & 0.023 & 0.049 & 0.015 & 0.004 & -1.5 & -0.3 \\
& 1.23 & 1.42 & 0.28 & 0.21 & 28.0 & 20.2 \\
\multirow{2}{*}{ SON } & -0.082 & 0.029 & 0.001 & 0.004 & 1.9 & -0.1 \\
& 1.14 & 1.47 & 0.21 & 0.20 & 20.9 & 19.7 \\
DJF & -0.047 & 0.021 & -0.015 & 0.003 & -3.0 & -0.1 \\
\hline
\end{tabular}

3.3. Different Latitude Zones. Figure 8 shows the mean LAI, uncertainty, and relative uncertainty for different latitudes. The GEOV2 and MODIS LAI profiles are very similar in all latitudes with the highest value (4.5) located in the tropical regions and smaller peaks $(2.0-2.5)$ around $20^{\circ} \mathrm{N}$. GEOV2 is lower $(\sim 0.57)$ than MODIS at $20^{\circ}-30^{\circ} \mathrm{N}$ (Figure $8(\mathrm{a})$ ). The highest average LAI values $(>2.1)$ are distributed in the tropical regions $\left(25^{\circ} \mathrm{N}-25^{\circ} \mathrm{S}\right)$ (Table 5).

The LAI uncertainty profiles show a higher plateau between $20^{\circ} \mathrm{S}$ and $60^{\circ} \mathrm{N}$ (Figure 8(c)). Both GEOV2 and MODIS display two uncertainty peaks at $25^{\circ} \mathrm{N}-25^{\circ} \mathrm{S}$ and $80^{\circ} \mathrm{N}-50^{\circ} \mathrm{N}$, respectively (Table 5 ). The relative uncertainties are $<25 \%$ for both products between $80^{\circ} \mathrm{N}$ and $60^{\circ} \mathrm{S}$ (Table 5). However, the MODIS relative uncertainty demonstrates a positive bias as compared to that of the GEOV2 at $25^{\circ} \mathrm{S}-60^{\circ} \mathrm{S}$ (Table 5).

The global LAI exhibits a slight and steady increase in the northern hemisphere $80^{\circ} \mathrm{N}-25^{\circ} \mathrm{N}$ (Figure 8(b)). GEOV2 shows a much larger increase in uncertainties than MODIS for all latitude zones except the northern higher latitude $\left(80^{\circ} \mathrm{N}-50^{\circ} \mathrm{N}\right.$, Table 5). The largest increase in uncertainties is observed for GEOV2 $(0.064 / 10 \mathrm{a})$ in $50^{\circ} \mathrm{N}-25^{\circ} \mathrm{N}$. The relative uncertainties for both products are relatively stable over the years. However, GEOV2 displays a small increasing trend in $80^{\circ} \mathrm{N}-50^{\circ} \mathrm{N}(0.03 / 10 \mathrm{a})$ (Table 5).

3.4. Altitudinal Patterns. Figure 9 shows the distribution of mean LAI values, uncertainties, and relative uncertainties along the altitude. The global mean LAI values are around 1.26 and 1.36 for GEOV2 and MODIS, respectively, at $<1000 \mathrm{~m}$ and decrease with the increase of altitude by about 0.21-0.23 for every $1000 \mathrm{~m}$ (Figure 9(a)). GEOV2 and MODIS show similar LAI profiles, although GEOV2 is slightly lower than MODIS at all altitudes (Table 6).

For both products, the highest uncertainties are associated to the low altitudes at $<1000 \mathrm{~m}$. The uncertainties decrease gradually with elevation at $0.038 / \mathrm{km}$ and $0.033 / \mathrm{km}$ for GEOV2 and MODIS, respectively. GEOV2 shows slightly higher uncertainties $(\sim 0.03)$ than that of MODIS at $<1000 \mathrm{~m}$, but the MODIS uncertainty is higher 

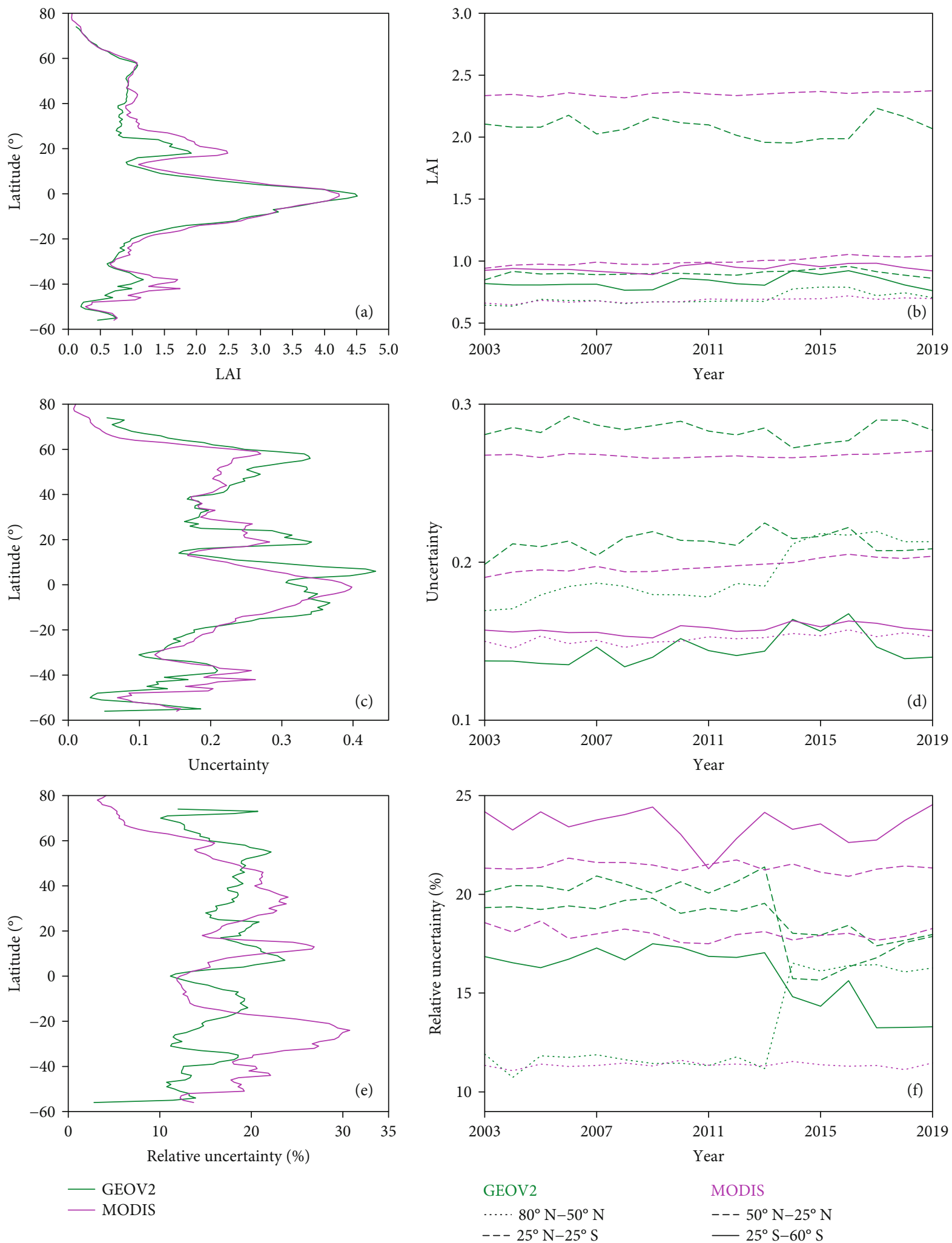

FIGURE 8: Latitudinal distribution of the mean and long-term trend of the GEOV2 and MODIS (a, b) LAI values, (c, d) uncertainties, and (e, f) relative uncertainties from 2003 to 2019 .

than that of the GEOV2 at all other altitude zones. Between 1500 and $3000 \mathrm{~m}$, both LAI and uncertainties are relatively stable in the altitudinal zone. The relative uncertainties are similar (16-17\%) for both products at $<1000 \mathrm{~m}$, but for all the other latitude zones, the relative uncertainties of MODIS are about $5 \%$ higher than those of the GEOV 2 . 
TABLE 5: Global average LAI, uncertainty, and relative uncertainty (first row) and their long-term trend (per decade, italicized row) for different latitude zones (2003-2019).

\begin{tabular}{|c|c|c|c|c|c|c|}
\hline \multirow{2}{*}{ Latitude zones } & \multicolumn{2}{|c|}{ LAI } & \multicolumn{2}{|c|}{ Uncertainty } & \multicolumn{2}{|c|}{ Relative uncertainty (\%) } \\
\hline & GEOV2 & MODIS & GEOV2 & MODIS & GEOV2 & MODIS \\
\hline \multirow{2}{*}{$80^{\circ} \mathrm{N}-50^{\circ} \mathrm{N}$} & 0.70 & 0.68 & 0.19 & 0.15 & 13.2 & 11.3 \\
\hline & 0.083 & 0.004 & 0.025 & 0.039 & 3.3 & 0.1 \\
\hline \multirow{2}{*}{$50^{\circ} \mathrm{N}-25^{\circ} \mathrm{N}$} & 0.90 & 1.00 & 0.21 & 0.20 & 18.9 & 21.4 \\
\hline & 0.088 & 0.008 & 0.064 & -0.001 & 1.9 & -0.2 \\
\hline \multirow{2}{*}{$25^{\circ} \mathrm{N}-25^{\circ} \mathrm{S}$} & 2.08 & 2.35 & 0.28 & 0.27 & 19.1 & 18.0 \\
\hline & 0.003 & 0.001 & 0.025 & -0.031 & -0.4 & -0.2 \\
\hline \multirow{2}{*}{$25^{\circ} \mathrm{S}-60^{\circ} \mathrm{S}$} & 0.83 & 0.94 & 0.14 & 0.16 & 15.9 & 23.5 \\
\hline & 0.056 & 0.003 & 0.017 & -0.006 & 1.4 & -0.1 \\
\hline
\end{tabular}

Between 2003 and 2019, the mean LAI at all altitudes increase slightly (Figure 9(b), Table 6). For GEOV2, the LAI increasing trends between $1000 \mathrm{~m}$ and $4000 \mathrm{~m}(>0.10 / 10 \mathrm{a})$ are higher than those below $1000 \mathrm{~m}$ $(<0.05 / 10 a)$. However, for MODIS, the LAI increasing trends range between $0.025 / 10 \mathrm{a}$ and $0.035 / 10 \mathrm{a}$ for different zones at $<4000 \mathrm{~m}$. The GEOV2 uncertainty values also show small increases during this period, whereas the MODIS uncertainty remains nearly stable (Table 6 ). The GEOV2 relative uncertainty at $<1000 \mathrm{~m}$ shows a negligible positive trend $(0.6 \% / 10 \mathrm{a})$ during this period, but the trend is negative at $>1000 \mathrm{~m}$. For GEOV2, the relative uncertainties at 3000$5000 \mathrm{~m}$ are all above $18 \%$ before 2013 , but reduced to be around 16\% after 2014 (Figure 9(f)). The MODIS relative uncertainty at $<4000 \mathrm{~m}$ also shows small decrease, but it increases above the altitude from 2003 to 2019.

\section{Discussion}

4.1. Global LAI and the Uncertainty. It is widely acknowledged that the global LAI has increased over the past two decades [1, $7,8]$. The coupling relationship between uncertainty and LAI shows that the LAI uncertainties have also increased during the same period (Table 3). High relative uncertainties are primarily located in ecologically transition regions. These regions correspond to areas with large differences in canopy structure $[24,37]$. The higher relative uncertainties in autumn and spring are related to the higher variations in LAI and uncertainties during these periods [38]. The different relative uncertainties between GEOV2 and MODIS at $>1000 \mathrm{~m}$ reveal the difficulty for LAI and uncertainty estimates in relatively higher elevations. Future studies should explore areas and periods with higher relative uncertainties.

Temporal stability of accuracy is one of the most important features to be evaluated when a series of maps is produced over time, and CEOS LPV requires such an assessment to achieve Stage 2 validation of a product. The product quality stability analysis provides a diagnostic tool that would allow product users to identify potential anomalies on analysis of long-term trends and provide insights for improving satellite products $[22,23]$. However, since there is no specific quality requirement for random errors currently, this study have referred to the GCOS stability requirement
( $10 \%$ or 0.25 per decade) as a proxy quality requirement for random errors. Compared with the requirement, all biome types from both GEOV2 and MODIS fall below the stability requirement over the seasons (Figure 5). At the pixel level, the DBF, ENF, and DNF show relatively low percentage of pixels that are below the quality requirement (Figure 6). These three forest types generally show higher relative uncertainties than EBF (Table 3(a)). The EBF is characterized by high LAI values and low uncertainties. Nevertheless, the good performance of EBF may be partly due to the saturation for high LAI values in the tropical forests (Figure 3). MODIS has also applied an artificial regularization for saturated retrievals, and thus, the LaiStdDev may not reflect the retrieval uncertainty for high LAI values [21, 39].

Appropriate configuration of LAI uncertainties is critical in dynamic models, as the errors in LAI may propagate into the final modeling results [40-42]. The LAI uncertainty is frequently set as an empirical percentage (10\%-20\%) of the LAI values [42-44]. Figure 3 shows that on average, the global uncertainty is about $11 \%$ of the LAI value and has substantial variations. The global relative uncertainty data (Figure 2) may be employed to set the pixel-specific uncertainties when the LAI products are assimilated into climate and ecosystem models [45]. The temporal variation of relative uncertainties could also be considered in future ecosystem and climate models.

4.2. Comparison with Other Studies. Some researchers have investigated the quality change across different product releases $[16,21,46]$; however, there is still a knowledge gap regarding the temporal variation of the LAI product uncertainties. Back in 2011, GCOS proposed an accuracy requirement as the maximum of 0.5 or $20 \%$ in absolute and relative terms (noted as GCOS-2011 below) [47]. Figure 10 shows the percentage of pixels that falls within the GCOS-2011 quality thresholds for uncertainty $(0.5)$ and relative uncertainty $(20 \%)$. For $88.7 \%$ of MODIS pixels, the reported uncertainties are below the GCOS-2011 requirement, slightly higher than that of GEOV2 (81.2\%). The number of pixels within the requirement for uncertainty is about 11-16\% lower from May to September than that from October to April (Table S1). For different biome types, the nonforest types clearly show higher percentage $(\sim 18 \%)$ 

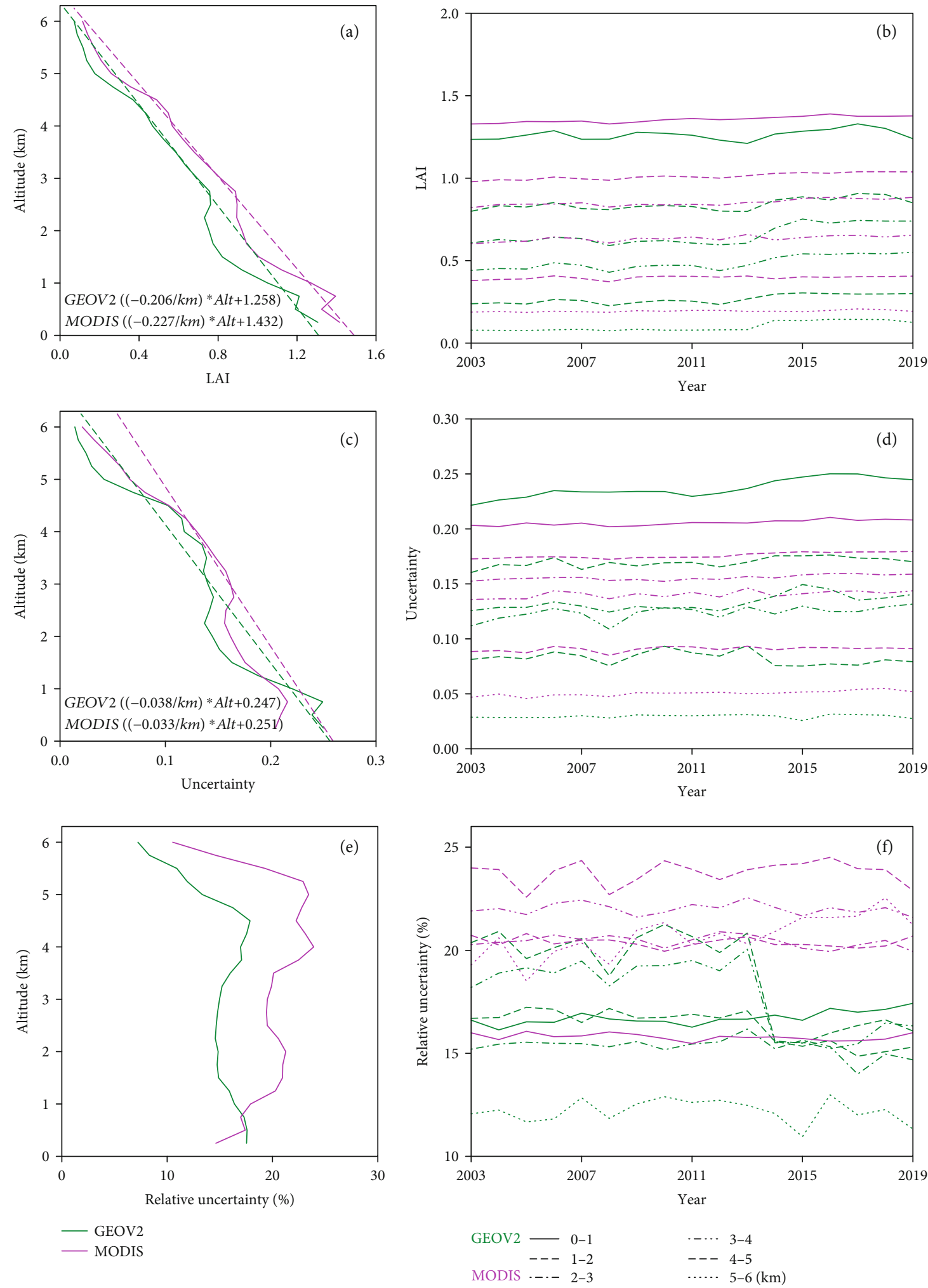

FIGURE 9: Altitudinal distribution of the average (left) and long-term trend (right) of the GEOV2 and MODIS (a, b) LAI values, (c, d) uncertainties, and (e, f) relative uncertainties from 2003 to 2019.

than the forest types to fall within the uncertainty threshold (Table S2). Both GEOV2 and MODIS show similar percentage of good retrievals to fall with the relative uncertainty threshold. Seasonally, both products exhibit lower percentage in spring and autumn and higher in summer and winter (Table S1). This may be attributed to the higher relative uncertainties for vegetation LAI during spring and autumn (Figure $7(\mathrm{c})$ ). There is no clear 
TABLE 6: Global average LAI, uncertainty, and relative uncertainty (first row) and their long-term trend (per decade, italicized row) for different altitude zones (2003-2019).

\begin{tabular}{|c|c|c|c|c|c|c|}
\hline \multirow{2}{*}{ Altitude (m) } & \multicolumn{2}{|c|}{ LAI } & \multicolumn{2}{|c|}{ Uncertainty } & \multicolumn{2}{|c|}{ Relative uncertainty (\%) } \\
\hline & GEOV2 & MODIS & GEOV2 & MODIS & GEOV2 & MODIS \\
\hline \multirow{2}{*}{$0-1000$} & 1.26 & 1.36 & 0.24 & 0.21 & 16.7 & 15.8 \\
\hline & 0.048 & 0.034 & 0.019 & 0.004 & 0.6 & -0.1 \\
\hline \multirow{2}{*}{$1000-2000$} & 0.84 & 1.01 & 0.17 & 0.18 & 16.3 & 20.4 \\
\hline & 0.108 & 0.037 & 0.017 & 0.005 & -0.5 & -0.1 \\
\hline \multirow{2}{*}{$2000-3000$} & 0.66 & 0.85 & 0.13 & 0.16 & 15.3 & 20.4 \\
\hline & 0.146 & 0.033 & 0.011 & 0.004 & 0.1 & -0.2 \\
\hline \multirow{2}{*}{$3000-4000$} & 0.49 & 0.63 & 0.12 & 0.14 & 17.9 & 22.0 \\
\hline & 0.119 & 0.025 & 0.015 & 0.004 & -1.3 & -0.1 \\
\hline \multirow{2}{*}{$4000-5000$} & 0.27 & 0.40 & 0.08 & 0.09 & 18.8 & 23.8 \\
\hline & 0.078 & 0.012 & 0.007 & 0.002 & -1.1 & 0.2 \\
\hline \multirow{2}{*}{ 5000-6000 } & 0.10 & 0.19 & 0.03 & 0.05 & 12.2 & 20.7 \\
\hline & 0.061 & 0.007 & 0.006 & 0.004 & 1.3 & 1.6 \\
\hline
\end{tabular}

(\%)

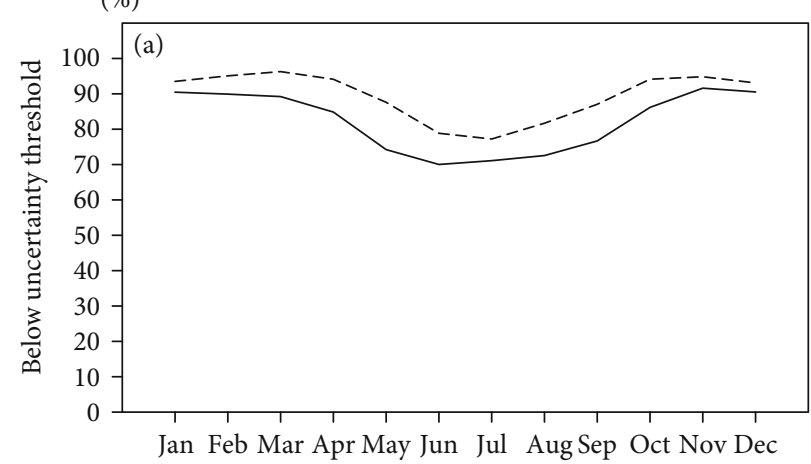

(\%)

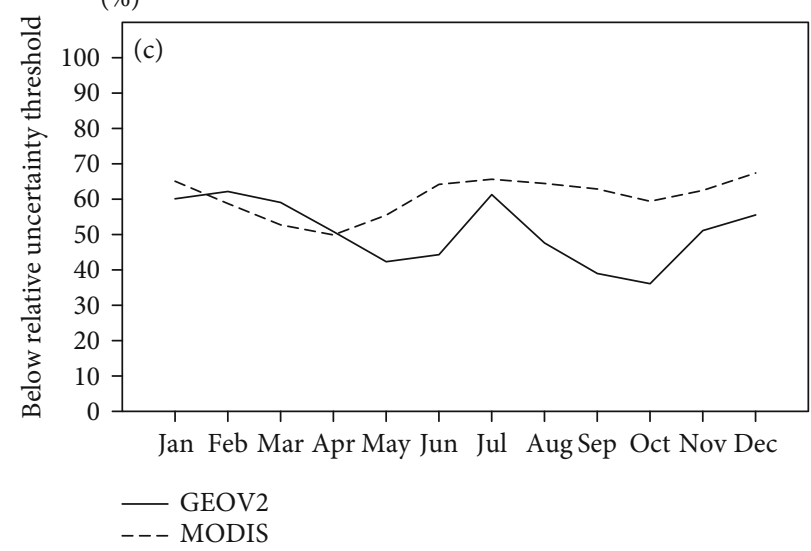

$(\%)$

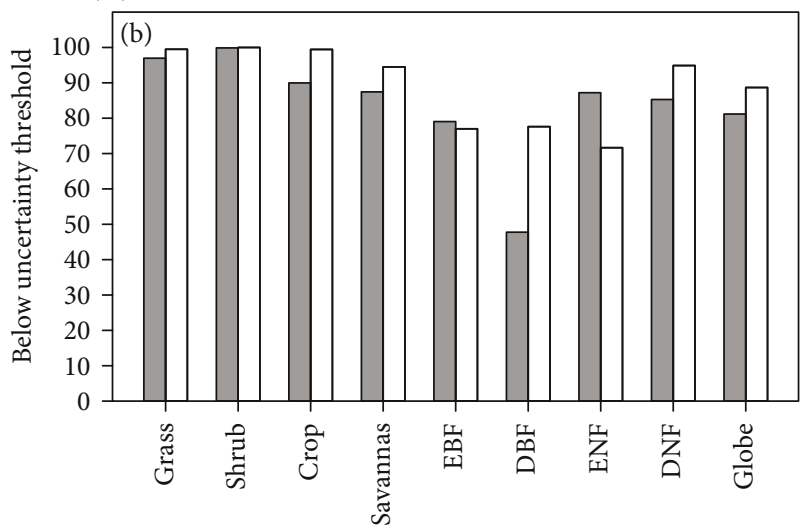

(\%)

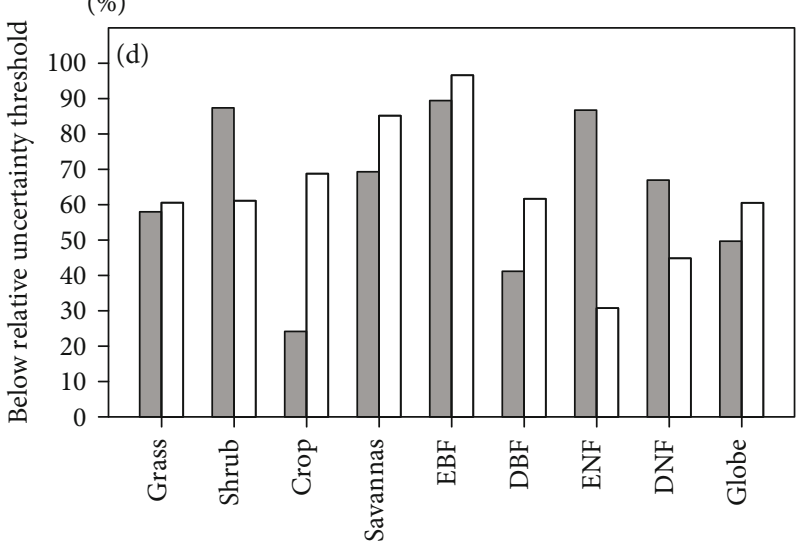

GEOV2

$\square$ MODIS

FIGURE 10: Percentages of GEOV2 and MODIS pixels that are below the GCOS-2011 quality requirements for (a, b) uncertainties and (c, d) relative uncertainties, respectively. (b, d) Statistics for different biome types. Percentages calculated as the ratio of the number of pixels that are within the threshold to the total number of valid retrievals.

difference between the forest and nonforest biome types, but EBF shows the highest percentage of good retrievals (>89\%, Table S2).
Results from Figure 10 can be compared with earlier studies which explored the GEOV1 and MODIS C5 LAI and uncertainties [24]. GEOV2 (1.16) exhibits a lower 
average LAI than the GEOV1 (1.55), whereas the MODIS average LAI remains nearly unchanged in different releases (1.43 vs. 1.28 for C5 and C6, respectively). The GEOV2 average uncertainty for EBF (0.37) has significantly decreased as compared to that of the GEOV1 (0.66), which leads to much higher percentage of pixels that are below the GCOS-2011 quality requirement than the earlier release (Figure 10). However, the quantitative uncertainties in GEOV1 (LAI_ ERR) were computed using the training dataset, and they reflect the sensitivity of the product to the input reflectance values [26]. Due to the different uncertainty definitions between GEOV1 and GEOV2, the quality improvement for EBF should be interpreted with caution. For MODIS, the same uncertainty definitions were applied for both releases. Compared to MODIS C5, the uncertainties for MODIS C6 have increased from 0.17 to 0.20 and the relative uncertainties from $11.4 \%$ to $16.7 \%$. Our earlier studies have shown that $93.2 \%$ of the MODIS C5 retrievals are within the absolute uncertainty $(0.5)$ and $78.5 \%$ within the relative uncertainty (20\%) requirements, respectively [24]. Compared to the earlier release, the MODIS retrievals remained stable in terms of the percentage of good retrievals for uncertainties (93.9\%) and but deteriorated for relative uncertainties (69.4\%, Figure 10).

On a regional scale, both physical and theoretical uncertainties of the current LAI products can vary by $>2.0$ from year to year [14]. The large temporal instability of the uncertainties shows that caution should be taken in studying the long-term trend of the LAI products, especially at a regional scale [14].

4.3. Limitations of the Study. GEOV2 shows a steady increase in LAI and uncertainty from 2003 to 2019 (Figure 4). The temporal profile is impaired by the change of the SPOT/VEGETATION to the PROBA-V in 2014. The sensor shift has caused mixed effects for different biome types (Figure 6). For grasses, crops, shrubs, and EBF, the relative uncertainties have decreased with the new sensor. But for other biome types, the relative uncertainties have increased since 2014 (Figure 6). The temporal anomaly reveals an algorithm deficit for cross-sensor performance which may have led to false increase in LAI and uncertainties. These anomalies and deficits should be diagnosed and be mitigated during the reprocessing stage. More studies are required to explain the differences in different variations to achieve consistent longterm trend both spatially and temporally. Before this, global long-term LAI change should be interpreted with caution because of the uncertainty variations. For MODIS, no clear seasonal and latitudinal trends are observed for the relative uncertainties, showing very stable relative uncertainties over the study period. The continuous observation provided by MODIS offers a clear advantage in studying the global LAI and the uncertainty trends. Nevertheless, this advantage could be dissolved because of the MODIS sensor degradation [48, 49]. Further analysis can be performed with the succeeding LAI products generated by the Sentinel-3 and VIIRS sensors for GEOV2 and MODIS, respectively $[50,51]$.

This study is limited by the different theoretical uncertainties of GEOV2 and MODIS. The GEOV2 uncertainties are computed as the RMSE between the final 10-day value and the daily estimates in the compositing period (Table 2). Essentially, they represent the deviation of the retrievals within a compositing window. For MODIS, the uncertainty represents the deviations of the retrievals from the mean acceptable LAI values in the LUT method. Nevertheless, both GEOV2 and MODIS product uncertainties are introduced in the product generation process because of deficiencies in the input data, models, and the retrieval algorithms. They are conceptually similar and are analogous to the product precision.

This study shows that the uncertainty layers provided in the products have enabled temporal analysis of the product quality variations over decades. However, the theoretical uncertainties exploited in this and other studies [7, 21, 24] are not equivalent to the product physical uncertainties. The latter are derived through validation with reference data from field measurements and high-resolution remote sensing estimates $[14,52]$. Such validation studies are critical to evaluate whether the LAI products can meet the accuracy requirement as proposed by the application community $[11,14]$. The temporal variability was calculated as the temporal change of the LAI theoretical uncertainties per decade, which is essentially different from the GCOS definition for product stability [11]. For a more robust study, long-term high-resolution reference data are required to validate the LAI products, the theoretical uncertainties, and the long-term stability $[14,52]$.

\section{Conclusion}

With the availability of various global satellite products, it is crucial to understand the product uncertainties and their variations in order to correctly interpret the products and the global trends and to target efforts to improve the products. This study investigated the spatial and temporal variations of the global LAI and the product uncertainties, capitalizing on the quality layers provided in global GEOV2 and MODIS LAI products. The global LAI has increased by $0.042 / 10 \mathrm{a}$ and 0.034/10a for GEOV2 and MODIS, respectively, from 2003 to 2019. The MODIS uncertainty and relative uncertainty have remained stable over the study period, while GEOV2 exhibits an increase in uncertainty (0.016/10a) and relative uncertainty $(0.3 \% / 10 \mathrm{a})$, especially during the growing season (April-October). The temporal instability revealed in this study would allow users to identify anomalies in products for future improvement. The uncertainty increase for GEOV2 is partly attributed to the sensor shift in the product series. The cross-sensor consistency should be improved for the forthcoming GEOV2 data processing.

Due to the more complex structure, forest biomes tend to show higher uncertainty and relative uncertainty values than nonforest biomes. Therefore, future studies should focus on improving the LAI quality for forest types. Compared to earlier releases, GEOV2 and MODIS did no show clear improvement in terms of the percentage of good retrievals for uncertainties and relative uncertainties.

Exploration of the long-term LAI quality information provides an in-depth evaluation of its quality. As various space agencies continue to provide product quality quantification, the uncertainty estimates have become standard 
elements of satellite products [53]. Current QQIs provided in the products are as diverse as the product algorithms themselves. The differences in product uncertainty definitions have complicated the comparison of different product quality. Nonetheless, this study highlights the importance of analyzing the long-term variations of the different QQIs provided in the products. Future research effort should focus on areas and periods with high uncertainties. For global vegetation change studies using satellite LAI products, much attention should be focused on LAI uncertainties and relative uncertainties. Other LAI products, such as the EUMESAT Polar System (EPS), PROBA-V, and VIIRS, could also be analyzed to explore their quality variation. Furthermore, similar studies can be performed for other products, e.g., the fraction of absorbed photosynthetically active radiation (FAPAR) that contains the quality indicators.

\section{Data Availability}

The GEOV2 and MODIS LAI data used in the study are openly available from the websites listed in the acknowledgments.

\section{Conflicts of Interest}

The authors declare that they have no competing interests regarding the publication of this article.

\section{Authors' Contributions}

H.F. performed the conceptualization, methodology, writing, and supervision. Y.W. collected data and performed the analysis with help from Y.Z. and S.L. All authors contributed to the writing-review of the manuscript.

\section{Acknowledgments}

This study was supported by the National Key Research and Development Program of China (2016YFA0600201). We are thankful for the GEOV2 (http://land.copernicus.eu/global/ products/lai) and MODIS (https://earthdata.nasa.gov/) projects that provided the global LAI data.

\section{Supplementary Materials}

Figure S1: density scatter plots between LAI and the associated uncertainties for GEOV2 (left) and MODIS (right) for different biome types. Table S1: the percentage of GEOV2 and MODIS pixels that are below the GCOS-2011 quality requirements for uncertainty and relative uncertainty, respectively, in different months. Table S1: the percentage of GEOV2 and MODIS pixels that are below the GCOS2011 quality requirements for uncertainty and relative uncertainty, respectively, in different months. (Supplementary Materials)

\section{References}

[1] H. Fang, F. Baret, S. Plummer, and G. Schaepman-Strub, “An overview of global leaf area index (LAI): methods, products, validation, and applications," Reviews of Geophysics, vol. 57, no. 3, pp. 739-799, 2019.

[2] J. M. Chen, W. Ju, P. Ciais et al., "Vegetation structural change since 1981 significantly enhanced the terrestrial carbon sink," Nature Communications, vol. 10, no. 1, article 4259, 2019.

[3] S. Piao, X. Wang, T. Park et al., "Characteristics, drivers and feedbacks of global greening," Nature Reviews Earth \& Environment, vol. 1, no. 1, pp. 14-27, 2019.

[4] Z. Zeng, S. Piao, L. Z. X. Li et al., "Impact of earth greening on the terrestrial water cycle," Journal of Climate, vol. 31, no. 7, pp. 2633-2650, 2018.

[5] L. Chen and P. A. Dirmeyer, "Adapting observationally based metrics of biogeophysical feedbacks from land cover/land use change to climate modeling," Environmental Research Letters, vol. 11, no. 3, pp. 1-14, 2016.

[6] P. J. Lawrence, J. J. Feddema, G. B. Bonan et al., "Simulating the biogeochemical and biogeophysical impacts of transient land cover change and wood harvest in the community climate system model (CCSM4) from 1850 to 2100," Journal of Climate, vol. 25, no. 9, pp. 3071-3095, 2012.

[7] C. Jiang, Y. Ryu, H. Fang, R. Myneni, M. Claverie, and Z. Zhu, "Inconsistencies of interannual variability and trends in longterm satellite leaf area index products," Global Change Biology, vol. 23, no. 10, pp. 4133-4146, 2017.

[8] S. Piao, G. Yin, J. Tan et al., "Detection and attribution of vegetation greening trend in China over the last 30 years," Global Change Biology, vol. 21, no. 4, pp. 1601-1609, 2015.

[9] N. Mahowald, F. Lo, Y. Zheng et al., "Projections of leaf area index in earth system models," Earth System Dynamics, vol. 7, no. 1, pp. 211-229, 2016.

[10] J. P. Boisier, N. de Noblet-Ducoudré, and P. Ciais, "Historical land-use-induced evapotranspiration changes estimated from present-day observations and reconstructed land-cover maps," Hydrology and Earth System Sciences, vol. 18, no. 9, pp. 35713590, 2014.

[11] GCOS, The Global Observing System for Climate: Implementation Needs (GCOS-200), World Meteorological Organization, 2016, https://library.wmo.int/opac/doc_num.php?explnum_ $\mathrm{id}=3417$.

[12] L. A. Brown, C. Meier, H. Morris et al., "Evaluation of global leaf area index and fraction of absorbed photosynthetically active radiation products over North America using Copernicus Ground Based Observations for Validation," Remote Sensing of Environment, vol. 247, article 111935, 2020.

[13] M. Claverie, E. F. Vermote, M. Weiss, F. Baret, O. Hagolle, and V. Demarez, "Validation of coarse spatial resolution LAI and FAPAR time series over cropland in Southwest France," Remote Sensing of Environment, vol. 139, pp. 216-230, 2013.

[14] H. Fang, Y. Zhang, S. Wei et al., "Validation of global moderate resolution leaf area index (LAI) products over croplands in northeastern China," Remote Sensing of Environment, vol. 233, article 111377, 2019.

[15] B. Ogutu, J. Dash, and T. P. Dawson, "Evaluation of leaf area index estimated from medium spatial resolution remote sensing data in a broadleaf deciduous forest in southern England, UK," Canadian Journal of Remote Sensing, vol. 37, no. 4, pp. 333-347, 2011.

[16] H. Fang, S. Wei, and S. Liang, "Validation of MODIS and CYCLOPES LAI products using global field measurement data," Remote Sensing of Environment, vol. 119, pp. 43-54, 2012. 
[17] S. Garrigues, R. Lacaze, F. Baret et al., "Validation and intercomparison of global leaf area index products derived from remote sensing data," Journal of Geophysical Research, vol. 113, article G02028, 2008.

[18] U. Gessner, M. Niklaus, C. Kuenzer, and S. Dech, "Intercomparison of leaf area index products for a gradient of subhumid to arid environments in west Africa," Remote Sensing, vol. 5, pp. 1235-1257, 2013.

[19] S. Mayr, C. Kuenzer, U. Gessner, I. Klein, and M. Rutzinger, "Validation of earth observation time-series: a review for large-area and temporally dense land surface products," Remote Sensing, vol. 11, no. 22, article 2616, 2019.

[20] B. Xu, T. Park, K. Yan et al., "Analysis of global LAI/FPAR products from VIIRS and MODIS sensors for spatiotemporal consistency and uncertainty from 2012-2016," Forests, vol. 9, no. 2, article 73, 2018.

[21] K. Yan, J. Pu, T. Park et al., "Performance stability of the MODIS and VIIRS LAI algorithms inferred from analysis of long time series of products," Remote Sensing of Environment, vol. 260, article 112438, 2021.

[22] M. Padilla, S. Stehman, J. Litago, and E. Chuvieco, “Assessing the temporal stability of the accuracy of a time series of burned area products," Remote Sensing, vol. 6, no. 3, pp. 2050-2068, 2014.

[23] H. Fang, Y. Wang, Y. Zhang, and S. Li, "Long-term variation of global LAI and the uncertainty: Analysis of the GEOV2 and MODIS LAI products," in IGARSS 2020 - 2020 IEEE International Geoscience and Remote Sensing Symposium, pp. 28902893, Waikoloa, HI, USA, September 2020.

[24] H. Fang, C. Jiang, W. Li et al., "Characterization and intercomparison of global moderate resolution leaf area index (LAI) products: analysis of climatologies and theoretical uncertainties," Journal of Geophysical Research - Biogeosciences, vol. 118, no. 2, pp. 529-548, 2013.

[25] J. Horn and K. Schulz, "Post-processing analysis of MODIS leaf area index subsets," Journal of Applied Remote Sensing, vol. 4, no. 1, article 043557, 2010.

[26] F. Baret, M. Weiss, R. Lacaze et al., "GEOV1: LAI and FAPAR essential climate variables and FCOVER global time series capitalizing over existing products. Part1: principles of development and production," Remote Sensing of Environment, vol. 137, pp. 299-309, 2013.

[27] F. Baret, J. Morissette, R. Fernandes et al., "Evaluation of the representativeness of networks of sites for the global validation and intercomparison of land biophysical products: proposition of the CEOS-BELMANIP," IEEE Transactions on Geoscience and Remote Sensing, vol. 44, no. 7, pp. 1794-1803, 2006.

[28] F. Baret, O. Hagolle, B. Geiger et al., "LAI, fAPAR and fCover CYCLOPES global products derived from vegetation: Part 1 : principles of the algorithm," Remote Sensing of Environment, vol. 110, no. 3, pp. 275-286, 2007.

[29] A. Verger, F. Baret, and M. Weiss, "Algorithm Theoretical Basis Document, Leaf Area Index (LAI), Fraction of Absorbed Photosynthetically Active Radiation (FAPAR), Fraction of green Vegetation Cover (FCover), Collection $1 \mathrm{~km}$, Version 2," no. I1.41, 2019https://land.copernicus.eu/global/sites/cgls .vito.be/files/products/CGLOPS1_ATBD_LAI1km-V2_I1.41 .pdf.

[30] K. Yan, T. Park, G. Yan et al., "Evaluation of MODIS LAI/FPAR product collection 6. Part 1: consistency and improvements," Remote Sensing, vol. 8, no. 5, article 359, 2016.
[31] K. Yan, T. Park, G. Yan et al., "Evaluation of modis lai/fpar product collection 6. Part 2: validation and intercomparison," Remote Sensing, vol. 8, no. 6, p. 460, 2016.

[32] R. B. Myneni, R. Ramakrishna, R. Nemani, and S. W. Running, "Estimation of global leaf area index and absorbed PAR using radiative transfer models," IEEE Transactions on Geosciences and Remote Sensing, vol. 35, no. 6, pp. 1380-1393, 1997.

[33] Wenze Yang, Bin Tan, Dong Huang et al., "MODIS leaf area index products: from validation to algorithm improvement," IEEE Transactions on Geoscience and Remote Sensing, vol. 44, no. 7, pp. 1885-1898, 2006.

[34] Y. Knyazikhin, J. V. Martonchik, R. B. Myneni, D. J. Dine, and S. W. Running, "Synergistic algorithm for estimating vegetation canopy leaf area index and fraction of absorbed photosynthetically active radiation from MODIS and MISR data," Journal of Geophysical Research, vol. 103, pp. 32, 257-332, 76, 1998.

[35] A. Verger, F. Baret, and M. Weiss, "Near real-time vegetation monitoring at global scale," IEEE Journal of Selected Topics in Applied Earth Observations and Remote Sensing, vol. 7, no. 8, pp. 3473-3481, 2014.

[36] M. A. Friedl, D. Sulla-Menashe, B. Tan et al., "MODIS Collection 5 global land cover: algorithm refinements and characterization of new datasets," Remote Sensing of Environment, vol. 114 , no. 1 , pp. 168-182, 2010.

[37] H. Fang, W. Li, and R. Myneni, "The impact of potential land cover misclassification on MODIS leaf area index (LAI) estimation: a statistical perspective," Remote Sensing, vol. 5, no. 2, pp. 830-844, 2013.

[38] H. Fang, W. Li, S. Wei, and C. Jiang, "Seasonal variation of leaf area index (LAI) over paddy rice fields in ne China: intercomparison of destructive sampling, LAI-2200, digital hemispherical photography (DHP), and AccuPAR methods," Agricultural and Forest Meteorology, vol. 198-199, pp. 126$141,2014$.

[39] Y. Knyazikhin, J. Glassy, J. L. Privette et al.et al., MODIS Leaf Area Index (LAI) and Fraction of Photosynthetically Active Radiation Absorbed by Vegetation (FPAR) Product (MOD15) Algorithm Theoretical Basis Document, p. 126, 1999, http:// modis.gsfc.nasa.gov/data/atbd/land_atbd.php.

[40] A. L. Barbu, J. C. Calvet, J. F. Mahfouf, and S. Lafont, "Integrating ASCAT surface soil moisture and GEOV1 leaf area index into the SURFEX modelling platform: a land data assimilation application over France," Hydrology and Earth System Sciences Discussions, vol. 10, pp. 9057-9103, 2013.

[41] S. Boussetta, G. Balsamo, E. Dutra, A. Beljaars, and C. Albergel, "Assimilation of surface albedo and vegetation states from satellite observations and their impact on numerical weather prediction," Remote Sensing of Environment, vol. 163, pp. 111126, 2015.

[42] Y. Xie, P. Wang, X. Bai et al., "Assimilation of the leaf area index and vegetation temperature condition index for winter wheat yield estimation using landsat imagery and the CERES-Wheat model," Agricultural and Forest Meteorology, vol. 246, pp. 194-206, 2017.

[43] T. Viskari, B. Hardiman, A. R. Desai, and M. C. Dietze, "Model-data assimilation of multiple phenological observations to constrain and predict leaf area index," Ecological Applications, vol. 25, no. 2, pp. 546-558, 2015.

[44] C. Albergel, S. Munier, D. J. Leroux et al., "Sequential assimilation of satellite-derived vegetation and soil moisture products using SURFEX_v8.0: LDAS-Monde assessment over the 
Euro-Mediterranean area," Geoscientific Model Development, vol. 10, no. 10, pp. 3889-3912, 2017.

[45] C. Rüdiger, C. Albergel, J. F. Mahfouf, J. C. Calvet, and J. P. Walker, "Evaluation of the observation operator Jacobian for leaf area index data assimilation with an extended Kalman filter," Journal of Geophysical Research, vol. 115, article D09111, 2010.

[46] G. Fu and J. S. Wu, "Validation of MODIS collection 6 FPAR/LAI in the alpine grassland of the northern Tibetan plateau," Remote Sensing Letters, vol. 8, no. 9, pp. 831-838, 2017.

[47] GCOS, "Systematic Observation Requirements for SatelliteBased Products for Climate, 2011 Update, Supplemental Details to the Satellite-Based Component of the Implementation Plan for the Global Observing System for Climate in Support of the UNFCCC (2010 Update)," p. 138, 2011, https:// library.wmo.int/doc_num.php? explnum_id=3710.

[48] D. Wang, D. Morton, J. Masek et al., "Impact of sensor degradation on the MODIS NDVI time series," Remote Sensing of Environment, vol. 119, pp. 55-61, 2012.

[49] Y. Zhang, C. Song, L. E. Band, G. Sun, and J. Li, "Reanalysis of global terrestrial vegetation trends from MODIS products: browning or greening?," Remote Sensing of Environment, vol. 191, pp. 145-155, 2017.

[50] K. Yan, T. Park, C. Chen et al., "Generating global products of LAI and FPAR from SNPP-VIIRS data: theoretical background and implementation," IEEE Transactions on Geoscience and Remote Sensing, vol. 56, no. 4, pp. 2119-2137, 2018.

[51] A. Verger and A. Descals, "Algorithm Theoretical Basis Document, Leaf Area Index (LAI), Fraction of Absorbed Photosynthetically Active Radiation (FAPAR), Fraction of green Vegetation Cover (FCover), Collection 300m, Version 1.1," no. I1.01, 2021 https://land.copernicus.eu/global/sites/cgls.vito .be/files/products/CGLOPS1_ATBD_LAI300m-V1.1_I1.02 .pdf.

[52] L. A. Brown, R. Fernandes, N. Djamai et al., "Validation of baseline and modified Sentinel-2 level 2 prototype processor leaf area index retrievals over the United States," ISPRS Journal of Photogrammetry and Remote Sensing, vol. 175, pp. 71-87, 2021.

[53] WGClimate, "Space Agency Response to GCOS Implementation Plan (V2.2.1)," 2018, https://gcos.wmo.int/en/gcosimplementation-plan. 